\title{
APPLICATION OF FUTURE STUDIES AND SCENARIO PLANNING MODELS IN EARTHQUAKE CRISIS RESPONSE PLANNING
}

\author{
Hossein HOSSEINIKHAH, Asghar ZARRABI \\ University of Isfahan, Isfahan, Iran
}

\begin{abstract}
Future studies and scenario planning models have been applied in this investigation to formulate a useful planning for earthquake crisis response in Boyer Ahmad County, Iran, located on active faults. The objective of this study is to evaluate the vulnerable areas of urban and rural settlements, to identify the factors of casualties and losses, and to formulate the most desirable scenario in order to increase the resilience of the settlements in earthquake crisis. In this research, the vulnerable areas were detected by using the spatial analysis in ArcGIS. Cross-impact analysis and MICMAC were employed to identify the effective thrusters to reduce the financial losses of the citizens. The most desirable scenario was formulated by the Morphol scenario planning. The results indicated that about $27 \%$ of the city and 261 villages out of 977 are vulnerable to the risk. To reduce earthquake losses, a preventive scenario was outlined in order to enhance the resilience of the settlements against the earthquake crisis.
\end{abstract}

Key Words: earthquake, future studies, scenario planning, Boyer-Ahmad County.

\section{Introduction}

The World Bank has reported that the number of natural disasters worldwide has been rapidly raising from 1975 to 2005, while the amount of disasters has increased by about $400 \%$ and the annual number of affected people has nearly quadrupled, also depending on the rise in the population and urbanization (Parisi and Augenti 2013). ICRC (2011) showed that more than half of the world's population lives in high-risk areas. Meanwhile, earthquake has long been considered one of the most catastrophic and destructive natural phenomena, especially in developing countries (Dong and Shan 2013).

Iran is one of the earthquake-vulnerable countries in the world, suffering a lot of casualties and financial losses due to earthquakes over the past century (Yari et al. 2019). Regarding its geographical location, Iran, as a developing country, is one of the most vulnerable countries to hazards such as earthquakes, floods, and droughts. Meanwhile, the earthquake is considered to be the most common and destructive natural hazard in Iran, as a corollary to the fact that Iran's geographic zone, stretching from the Alpine-Himalayan seismic belt and extending to Zagros, Alborz, and Khorasan regions, is a highly seismic one. Iran, due to its location on the Alps-Himalayas seismic belt, ranks first in the number of earthquakes above 5.5 Richter and it ranks as one of the highest in terms of earthquake vulnerability and the number of people killed in such an event (UNDP 2004). In the last century, 18 earthquakes measuring greater than 7 on the Richter scale occurred in Iran, causing financial, physical, economic, and social losses in a large part of the country (Einali et al. 2020). Most of the physical and economic damage to such events is due to the lack of planning and weakness in the building standards, as well as in the infrastructures. Therefore, the readiness to face the future is one of the essential requirements of any nation; so, mankind should be prepared for the future to encounter its uncertainties (Bell 2003). Thus, ignoring these forecasts and changes in the external environment and being unprepared for such changes may lead to disastrous consequences. 
On the other hand, the speed of natural disasters today, such as earthquakes and changes in the natural environment, is so fast that they can no longer be dealt with in the traditional way, and they must be resolved using a new perspective and solution which in turn reflects the management of such disasters. In the meantime, one of the new approaches that can lead to financial vulnerability and the loss of causality during earthquake and humanitarian crises is represented by the future studies and scenario planning. Therefore, what underlines the significance of future studies in promoting safety and preventing disasters caused by earthquake natural disasters and future disaster management is the fact that, by imagining future disasters and events, there are provided appropriate solutions for disaster preparedness, prevention, and the mitigation of disasters while they are scientifically manageable (Treuer et al. 2018). Indeed, the main application of future studies in crisis management, such as earthquakes, is to identify the situation of future crises and to avoid being surprised by future events and phenomena such as natural disasters. It should be noted that the purpose of future studies and scenario planning in earthquake disaster management is to identify the influential indicators and to assess their severity, to identify the most critical factors in reducing or increasing the severity of damage, to examine the most important organizations and institutions in earthquake management before and after the crisis, and to tailor the most optimal earthquake management in the future to reduce the rate and severity of damages.

Since Boyer Ahmad is located in the Zagros seismic zone and the majority of cities and villages are located on the fault lines and close to three major faults known as: Dena fault, within a radius of less than $20 \mathrm{~km}$; Zagros fault, within a radius of 70 to $80 \mathrm{~km}$; and QatarKazerun fault, within $20 \mathrm{~km}$ of Yasuj (Zarrabi et al. 2015), it is one of the high-risk areas for earthquakes. Accordingly, the present study strived to identify the seismic zones of Boyer Ahmad as well as the potential earthquake-prone population centres by applying the spatial zoning and future studies and scenario planning approach while taking advantage of future studies and scenario planning. Attempts were made to determine the casualties and financial losses caused by the earthquake crisis in the county. In summary, the objectives of this study are as follows: (1) the identification and assessment of vulnerability of urban and rural settlements of Boyer Ahmad against the earthquake crisis (preparing the earthquake prone points of Boyer Ahmad); (2) the extraction of key proponents effective in reducing the causality and financial vulnerability of the earthquake crisis based on a cross-impact analysis approach; (3) the provision of possible scenarios for earthquake and the financial loss reduction in Boyer Ahmad assuming the scenario-based approach.

According to the studies conducted in Boyer Ahmad, earthquakes within the magnitude of 45.5 Richter are the most frequent, followed by a large average of 4-Richter earthquakes. The dominant focal points of the earthquakes are 10 to $30 \mathrm{~km}$ from the surface, and the seismic layer is 10 to $30 \mathrm{~km}$ deep. The largest earthquake had a magnitude of $6.3 \mathrm{MS}$ magnitude, $100 \mathrm{~km}$ far from Yasuj and $60 \mathrm{~km}$ from the earth surface (Zarrabi et al. 2015). There are a bulk of faults in the vicinity of Boyer Ahmad, the most important of which include (Fig. 1):

- Zagros Main Fault: the most important fault within the studied area which is 70 to $80 \mathrm{~km}$ from Yasuj (center of Boyer Ahmad).

- Qatar-Kazeroun Fault: the nearest piece is about $45 \mathrm{~km}$ from Yasuj.

- Dena Fault: this fault is the closest fault to Yasuj, less than $10 \mathrm{~km}$ to Yasuj.

- Michigan Fault: this fault is farther away than other faults in Yasuj, which is $85 \mathrm{~km}$ from Yasuj.

- Arjan Plain Fault: this fault is the farthest which is $100 \mathrm{~km}$ from Yasuj (Zarrabi et al. 2015). 


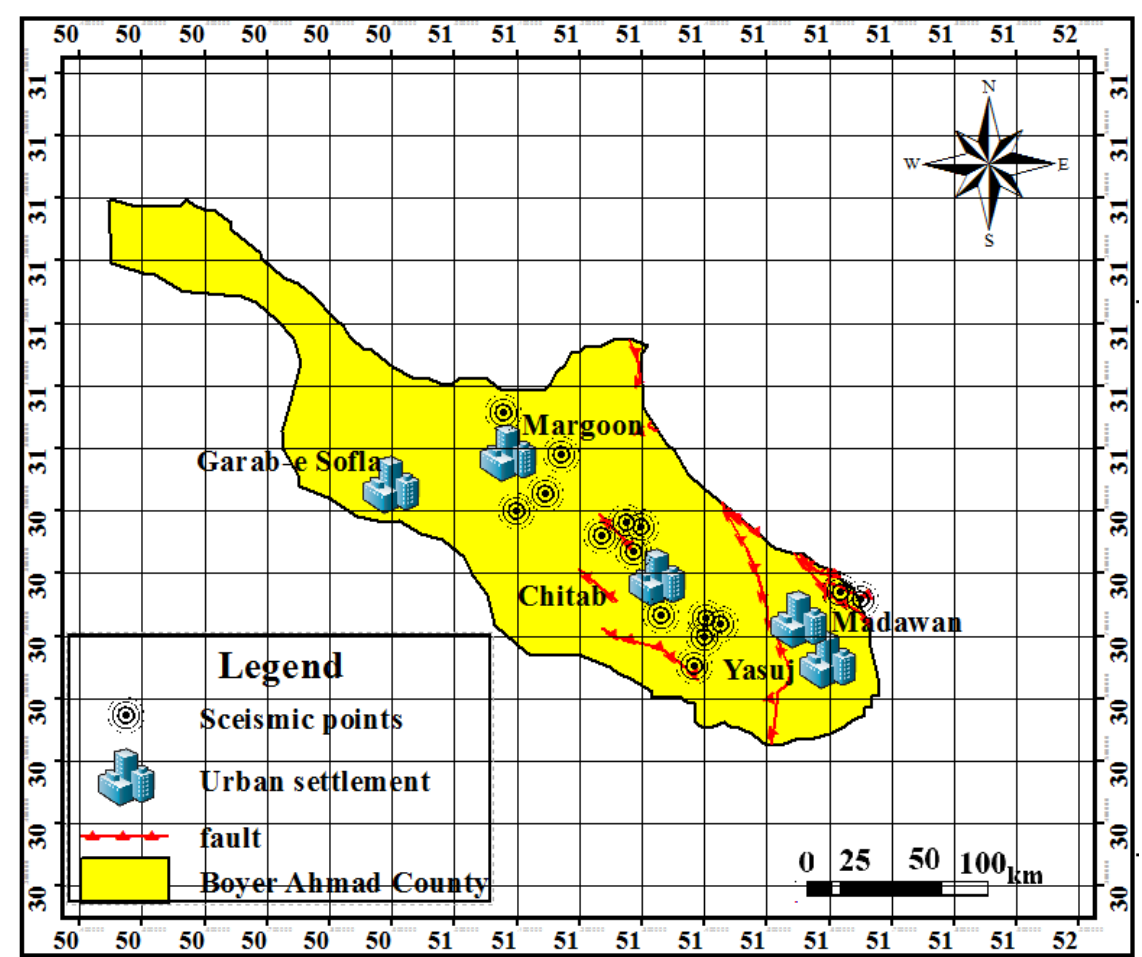

Fig. 1 - Active and passive faults and seismic points of Boyer Ahmad

The futures studies method can be one of the best optimal management techniques in the future when at any moment a crisis such as an earthquake may occur.

\section{Earthquakes}

Earthquakes are among the most catastrophic natural disasters to affect mankind (Dong and Shan 2013). Cascading natural hazards are urgent global issues that may cause catastrophic losses, affecting urban communities from the economic, social, and environmental point of view. Earthquakes and tsunamis can be concurrent threats to cities (De Risi et al. 2018). Natural processes that modulate the spatial and temporal occurrence of earthquakes include tectonic stress changes, migration of fluids in the crust, Earth tides, surface ice and snow loading, heavy precipitation, atmospheric pressure changes, sediment unloading and groundwater loss. Such processes perturb the stress on faults by only small amounts but, since rock failure in earthquakes is a critical process, nucleation of each event is ultimately brought about by a final, incremental change in stress (Foulger et al. 2017). An earthquake is a sudden, rapid shaking of the earth's crust caused by the breaking and shifting of tectonic plates beneath the earth's surface. This shaking can cause the collapse of buildings and bridges; and disruptions in gas, electric, and phone services; and it can trigger landslides, avalanches, flash floods, fires, and huge, destructive ocean waves (tsunamis). Structures constructed on unconsolidated landfill, old waterways, or other unstable soils are generally at greatest risk unless seismic mitigation has been utilized. Seismicity is not seasonal or climate-dependent and it can therefore occur at any time of the day or year (Haddow et al. 2017).

The threat of earthquakes will probably increase because of global urbanization, and thus millions of people are exposed to earthquakes. Although humans cannot prevent earthquakes, we can change the way we respond to them (Dong and Shan 2013). 
Earthquakes can cause different types of structural and non-structural damage in buildings (Vitorino et al. 2020). Earthquakes are among the most unpredictable and devastating natural disasters. Since 1900, earthquakes have caused 2.3 million deaths and they resulted in economic costs of an estimated $\$ 3.41$ trillion. The earthquake phenomenon as a natural hazard is causing high levels of vulnerability and damages to the structures around the world (Kassem et al. 2019). A recent review of significant earthquakes found that injuries were reported in only $56 \%$ of earthquakes with mortality that occurred between 1960 and 2009 and that 2 million earthquake injuries were reported worldwide in this period. Building design, geography and development indicators are important factors in earthquake vulnerability. There is substantial variation in the human impacts of earthquakes, and low levels of economic development have been associated with a higher earthquake morbidity and mortality suggesting that poorer countries face an increased risk due to a variety of characteristics of the built environment (Doocy et al. 2013).

The earthquake is an unpredictable natural phenomenon and a series of vibrations at the surface caused by the production of elastic (seismic) waves, and it is generally the sudden collapse of plates due to accumulated energy release (Kahandawa et al. 2018). The most important cause of the earthquake is the pressure between two or more adjacent geological structures as well as the increase in overburden within the rocks and the inner layers of the earth (Soltysik et al. 2017). In fact, high-grade earthquakes cause enormous physical losses, destruction, casualties, and psychological costs such as fear, anxiety, and distress (Liu et al. 2017).

\section{Futures studies}

The future is an uncharted territory. The future is often a scary place for organizational executives (Hines 2002). Bell (2002) defines future studies as an independent discipline that aims to study the future systematically. Futurists seek to discover, invent, present, test, and evaluate possible, probable and better futures (Bell 2002). For Bell (2002), futures studies is the discovery or invention, examination, evaluation, and suggestion of futures that may happen (possible), or are likely to happen (probable), aiming at improving the freedom and prosperity of the humankind (Bell 2002).

Futures studies encompass a lot of dimensions, including prediction, social foresight, changeable politics, and ideal imagery (Öner 2010). Futures studies, also called futurology, is the study of postulating possible, probable, and preferable futures and the worldviews and myths that underlie them (Sardar 2010). Future studies tend to be oriented towards the longer term - beyond the next two or three decades. It is essentially an open-ended and less definable process than forecasting and long-range planning. Often, futures studies are concerned with the sets of value considerations and preferences. Rather than assuming the given nature of larger causal relations, these are taken as open to question. There is an underlying shift from what it may be feasible under the given constraints to what it could or it should be possible and/or desirable - if we choose to alter the constraints upon present and future actions (McHale and Cordell McHale 1976).

The task of the futurist is to investigate this tree as a whole. Its branches define the alternative scenarios, which we might want to realize or avoid. More precisely, the received view is that the futurist should (i) construct alternative possible futures, (ii) assess the probability of alternative futures, and (iii) evaluate the preferability or desirability of alternative futures (Niiniluoto 2001). Futures studies are moving away from the pursuit to give accurate probabilities and foresight, and they attempt to provide technical information for people and organizations to control processes, information and structures. Futures studies are moving towards critical hermeneutical understanding, emancipatory dialects, and diversity (Kuosa 2011). Generally, future studies represent knowledge and art that helps people to identify the events, the opportunities and threats of the future, and to cleverly 
select desirable and sought-after futures from the among possible, believable and probable futures, so that they will not consider the future as rigid, decisive, definite and unchanged.

\section{Scenario planning}

Scenarios are tools for ordering the one's perceptions about alternative future environments in which one's decisions might be played out. Alternatively, scenarios are a set of organized ways to dream effectively about our own future (Chermack 2005). Scenario planning - or, alternatively, scenarios - is a predictive approach that aims to envisage alternative futures in the form of different - but internally consistent - configurations of new events and drivers of change (Vecchiato 2019). Scenario planning, also called scenario thinking or scenario analysis, is a strategic planning method that some organizations use to make flexible long-term plans. It is in large part an adaptation and generalization of the classic methods used by the military intelligence (Bradfield et al. 2005).

The scenario illustrates how the future may be shaped by the current situations and it includes a set of hypotheses about the key factors (Geneletti 2012). Scenario planning may involve aspects of systems thinking, specifically the recognition that many factors may combine in complex ways to sometime create surprising futures (due to non-linear feedback loops). The method also allows the inclusion of factors that are difficult to formalize, such as novel insights about the future, deep shifts in values, unprecedented regulations or inventions (Mendonça et al. 2009).

The systems thinking used in conjunction with scenario planning leads to plausible scenario storylines because the causal relationship between the factors can be demonstrated (Gausemeier et al. 1998). Scenario planning can take on a higher profile role in strategic planning in turbulent environments (Ramírez and Selsky 2014). Scenario planning aims to distinguish between what people understand as predictable and what they perceive as unpredictably uncertain, where the latter means not only not predicted but not predictable (Ramírez and Selsky 2014). Scenario planning is an effective method for examining future uncertainties and for investigating the assumptions in organizations. There are four potential boundaries concerning the practice and theory of scenario planning (Fig. 2): (1) a process boundary, (2) a planning system boundary, (3) a performance system boundary, and (4) an organizational and contextual environment boundary (Chermack 2005).

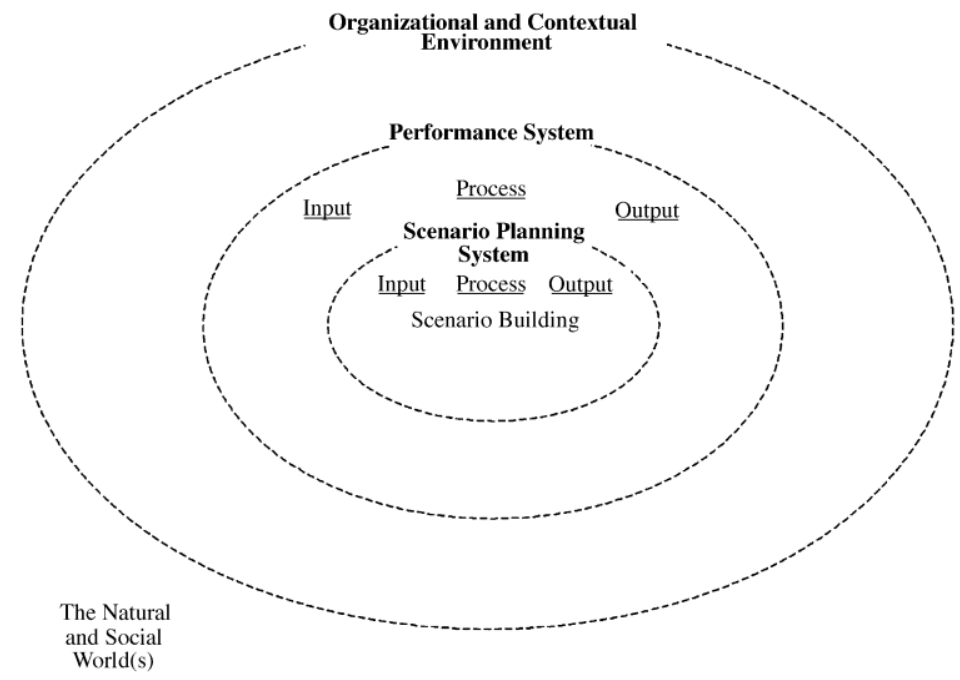

Fig. 2 - The boundaries of a theory of scenario planning 


\section{Methodology}

Boyer Ahmad is a county in Kohgiluyeh and Boyer Ahmad Province in Iran (Fig. 3). The capital is Yasuj, and the population of the city in 2016 was 299855 people with 77569 households. The number of cities in 2016 was five, including Yasuj, Chitab, Madwan, Margoon, and Garab-e Sofla, as well as four districts of Margoon, the central district, Ludab, and Kabegian, and 11 villages and 977 rural districts and oases.

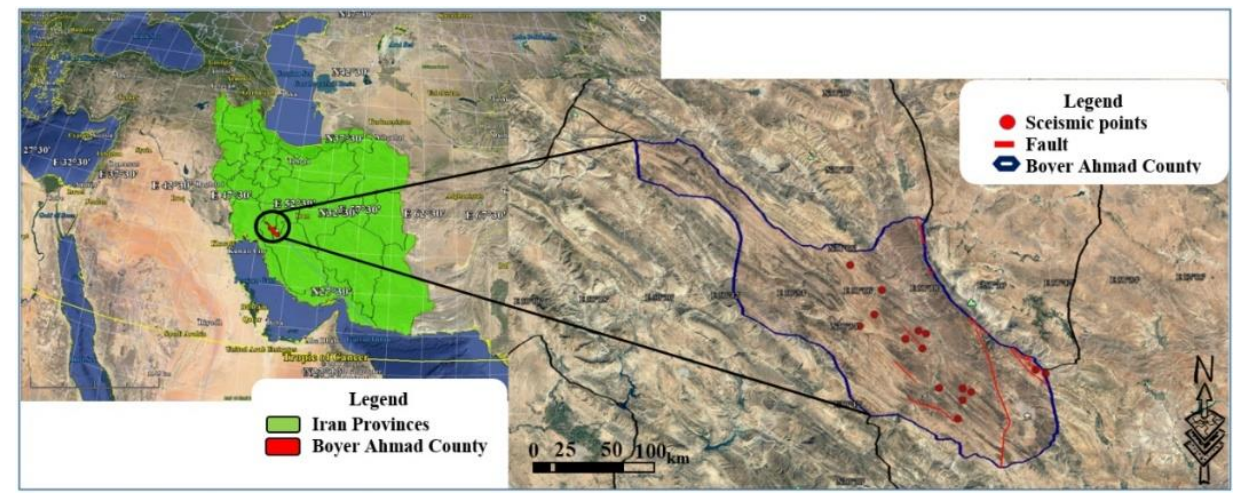

Fig. 3 - Spatial location of Boyer Ahmad in Kohgiluyeh and Boyer Ahmad Province and Iran

The research method is descriptive, analytical, structural-quasi-mathematical (a combination of quantitative/qualitative data) and it is an applied study in terms of research objectives. Different combinatorial methods, including the library method, the field method, and the Delphi method were used for data collection.

The study was analyzed in three parts. In the first part, the identification and zoning of vulnerable urban and rural settlements of Boyer Ahmad were carried out using the ARC GIS spatial analysis software and the GRA model. This part collected spatial and local layers from multiple sources, including satellite imagery, Google Earth software, the US Geological Survey, etc. (Table 1).

Type and source of data to measure the vulnerability

Table 1 of urban and rural settlements in earthquake crisis

\begin{tabular}{|c|c|c|}
\hline Parameter & Type & Source \\
\hline Fault lines & vector & Iranian Seismological Center \\
\hline Seismic points & vector & Google Earth Software \\
\hline Geology & vector & Geological Survey \& Mineral Explorations of Iran (GSI) \\
\hline Land use & vector & Organization of Natural Resources \\
\hline $\begin{array}{c}\text { Rural and urban } \\
\text { settlements }\end{array}$ & vector & The Ministry of Interior of the Islamic Republic of Iran \\
\hline $\begin{array}{c}\text { Communication } \\
\text { roads }\end{array}$ & vector & Ministry of Roads \& Urban Development \\
\hline Height & raster & United States Geological Survey \\
\hline Slope & raster & Extracted from Layer Height \\
\hline Aspect & vector & Geological Survey \& Mineral Explorations of Iran (GSI) \\
\hline River & vector & Iranian Ministry of Energy \\
\hline
\end{tabular}


In the second part, the MICMAC software (cross-impact analysis model) was used to identify the most effective key factors to reduce the vulnerability and financial loss of citizens in Boyer Ahmad in the earthquake crisis. The MICMAC works on the principle of multiplication properties of matrices (Kadam and Bandyopadhyay 2020). The MICMAC method for structural analysis is aimed at determining the most important variables within a system among a set of variables, initially specified by an expert committee, and establishing their role in the system. This is accomplished by studying the influence relation among the variables. Basically, MICMAC consists in the following three steps: (1) defining the relevant variables, (2) specifying the relations between the variables, (3) identifying the key variables (Villacorta et al. 2014).

The Cross-Impact Analysis ( $\mathrm{CIA})$ is based on cross-impact questions that allow individuals to easily estimate the relationships among $n$ events taken two at a time $(n(n-1) / 2$ comparisons) (Bañuls and Turoff 2011). The Cross-Impact Analysis is a powerful model in the MICMAC software for taking a set of binary future events and for examining the potential causal impacts that the expectation or occurrence of each event may have on the others in the set (Panula-Ontto et al. 2018). In this context, the Cross Impact Analysis is one of the most used methods to study the possible futures or scenarios by identifying the system's variables (Fig. 4) and the role they play in it (Villacorta et al. 2014). The degree of relationship is numbered between 0 and 3 , in which zero represents the lack of impact; one means weak impact; two means average impact, and three means high impact (Helmer 1977). So, if the number of known variables is $x$, the matrix $x \times x$ is obtained.

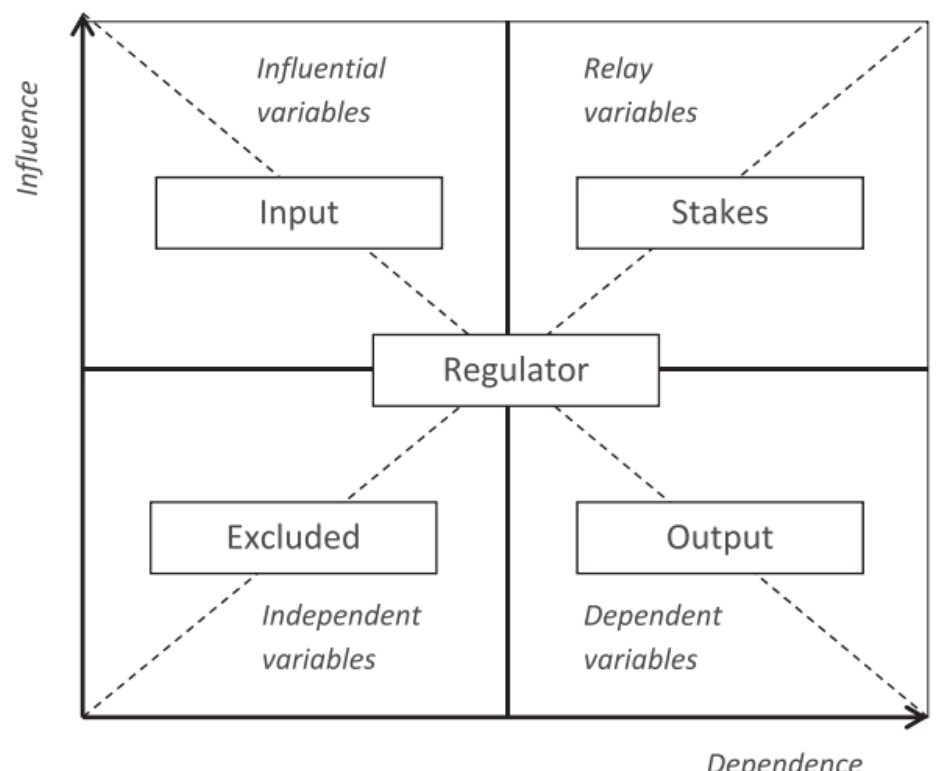

Fig. 4 - The influence-dependence plane

At this stage, the most effective and probable variables in reducing the causality and financial vulnerability in the earthquake crisis were identified through the experts and researchers in earthquake crisis management (20 experts and 15 researchers). In so doing, the provincial land preparation document was extracted and classified into 62 variables (Table 2). At this stage, experts and researchers were selected purposefully and identified using the Delphi method. Then, the effective variables in reducing causality and financial vulnerability of earthquake crisis in Boyer Ahmad were investigated. After the identification of variables and components, they were inserted into the cross-impact analysis matrix, and the degree of relationship between these variables was identified by the experts. Thus, the 
sum of the data of the row variables shows the extent of impact and the sum of the data of the column variables shows the degree of impact.

Table 2

Effective and probable factors for reducing the causality and financial vulnerability in the earthquake crisis in Boyer Ahmad

\begin{tabular}{|c|c|}
\hline $\begin{array}{l}\frac{0}{0} \\
\frac{\pi}{\frac{\pi}{2}} \\
\frac{\pi}{\pi}\end{array}$ & 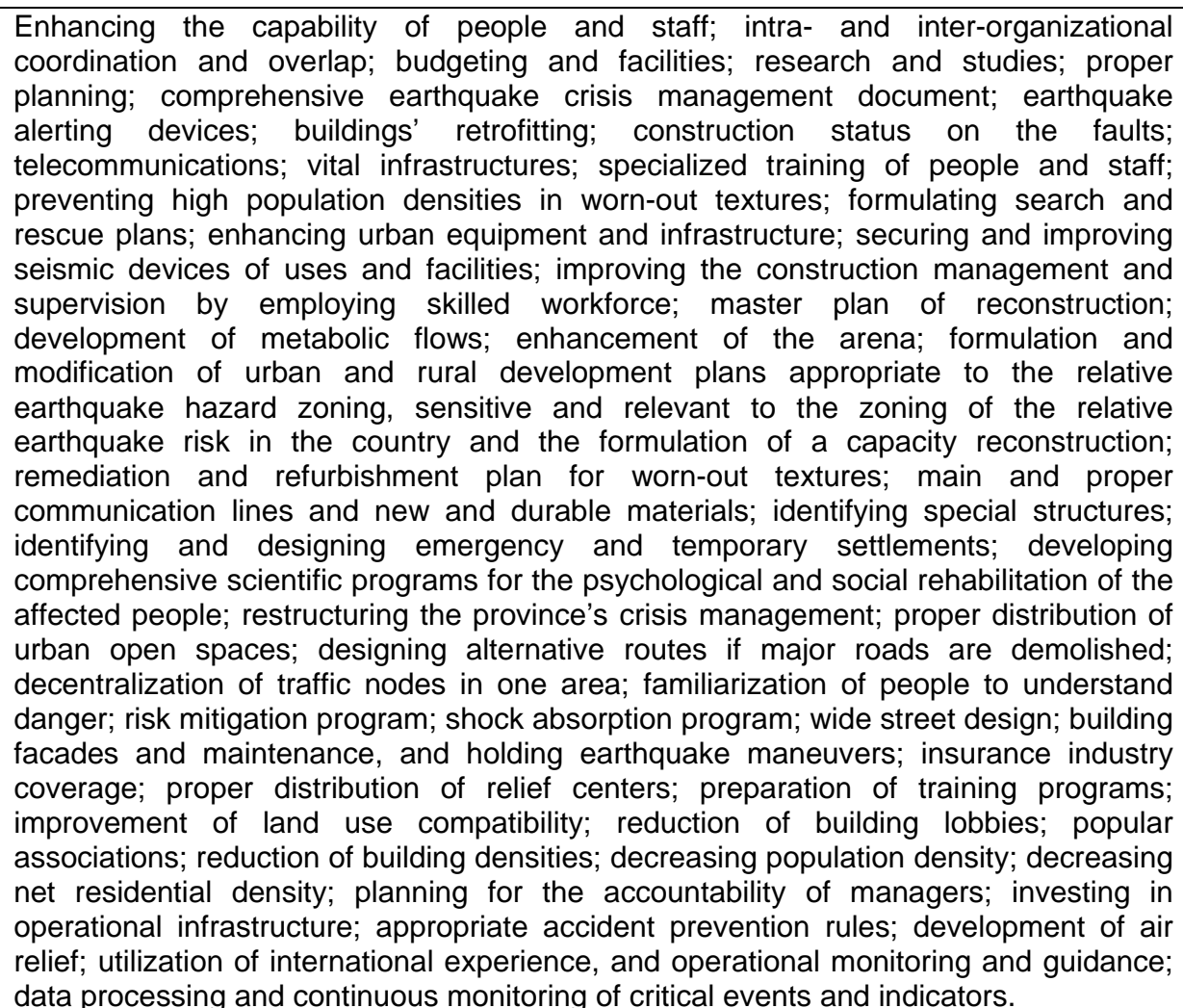 \\
\hline
\end{tabular}

Source: provincial preparation document and interview with provincial experts, researchers, and executive managers (2019)

In the third part, the Morphol scenario software was run to formulate the most desirable scenario to reduce the causality and financial vulnerability of the citizens in Boyer Ahmad against the earthquake crisis. The morphological analysis provides a structured method for ensuring consistency and relevance in scenario development. The morphological analysis strictly speaking on the study of forms - is well established as a method for modelling the structural relationships between objects and phenomena in several scientific fields (Johansen 2018). At this stage, the most important factors identified in Section II (Table 3) were given to the experts and researchers (15 experts and 10 researchers) in the field of earthquake crisis management to design different scenarios. The experts and researchers were selected purposefully and then, using the Delphi method, different scenarios were designed to reduce the causality and financial vulnerability of the earthquake crisis in Boyer Ahmad.

After identifying the effective factors using the MICMAC software, different hypotheses were made for each key factor. In this way, by scoring the different hypotheses of each key proponent, the final score for each hypothesis was determined; finally, the best scenarios 
were presented as the top scenarios. The relationships between hypotheses ranged from $0 \%$ to $100 \%$, such that $0 \%$ meant no impact and $100 \%$ meant a high impact (Taghvaei and Hosseinekhah 2018).

Table 3

Key factors

\begin{tabular}{|c|l|}
\hline Row & \multicolumn{1}{c|}{ Factors } \\
\hline 1 & Specialized training of people and staff \\
\hline 2 & Intra- and inter-organizational coordination and overlap \\
\hline 3 & Budgeting and facilities \\
\hline 4 & Research studies \\
\hline 5 & Proper planning \\
\hline 6 & Comprehensive earthquake crisis management document \\
\hline 7 & Earthquake alerting devices \\
\hline 8 & Buildings' retrofitting \\
\hline 9 & Construction status on faults \\
\hline 10 & Vital infrastructures \\
\hline 11 & Main and proper communication lines \\
\hline 12 & New and durable materials \\
\hline 13 & Telecommunications \\
\hline
\end{tabular}

Source: statistical processes derived from the Cross-Impact Analysis model and the MICMAC software (2019)

Future studies, in their literal sense, emerged virtually from the middle of the twentieth century and more scientifically as one of the planning tools in the mid-twentieth century at the RAND Corporation, the United States Armed Forces. In the present study, two methods of cross-impact analysis and scenario planning were used to conduct the research process. The term futurology or futures studies were first introduced in 1966 by Flechteim (Sardar 2010). Modern futures studies, as "a full-scale futures movement", developed after the end of World War II (Son 2015). The history of using the cross-impact analysis dates back to the 1960s (Godet and Durance 2011), but in recent years, Glenn and Gordon (2009) have pioneered the use and introduction of this method in future studies and they have used the method in identifying, classifying, and ranking the elements that influence the future of different systems (Glenn and Gordon 2009). The MICMAC analysis has been used in extensive research, including Kumar et al. (2019); for a policy framework for city eligibility analysis: TISM and fuzzy MICMAC (Kadam and Bandyopadhyay 2020); for modelling the passenger interaction process (PIP) framework, using the ISM and MICMAC approach (Panula-Ontto et al. 2018); the cross-impact analysis of Finnish electricity system with increased renewables (Thorleuchter and Van den Poel 2014); and the semantic compared cross-impact analysis.

Scenario planning history dates to the World War II, when scientists used computer simulation to identify the effects of a nuclear bomb. The scenario concept originates from the 1950s and it is ascribed to Kahn, at that time working at the RAND Corporation (Haasnoot and Middelkoop 2012). Also, he demonstrated with scenarios that the US military planning was based on 'wishful thinking' instead of 'reasonable expectations' (Bradfield et al. 2005). Generally, the first use of scenario planning was in military planning, in the 1950s, while in the 1980s, scenarios became mainstream in futures research (Haasnoot and Middelkoop 2012).

So far, no research has been conducted in Iran regarding the planning of earthquake response with an eye on the scenario-based approach. However, the scenario-based analysis has been used in extensive research, including Rodgers et al. (2020). These are including: the creation of an earthquake scenario in China (Zhang et al. 2018); a scenario- 
based model for earthquake emergency management effectiveness evaluation (Zolfaghari and Peyghaleh 2016); the development of optimization-based probabilistic earthquake scenarios for the city of Tehran (Valagussa et al. 2014); earthquake-induced rockfall hazard zoning (Verma and Bansal 2012); and earthquake precursory studies in India, with scenario and future perspectives.

\section{Results and Discussion}

Based on the geographical maps, Boyer Ahmad County has a high seismic potential due to being located among the four major faults, including Zagros, Qatar-Kazerun, Dena, Mishan, and Dasht-e Arjan. So that, the County of Boyer Ahmad has $321 \mathrm{~km}$ of fault lines according to the maps of fault lines. Although several factors are involved in the formation of the earthquake critical points in Boyer Ahmad County, the spatial and geometrical characteristics of fault lines have an important role in exacerbating the vulnerability of Boyer Ahmad population settlements. Final investigations show that the high vulnerability zones are adjacent to the fault lines in the County of Boyer Ahmad and the severity of earthquake hazards also decreases as the distance from the fault lines decreases. The survey and analysis of the final map shows that the north and south west and part of the southern district of Boyer Ahmad County have the highest risk of earthquake crisis and the main reason are the fault lines passing through these areas (Fig. 5).

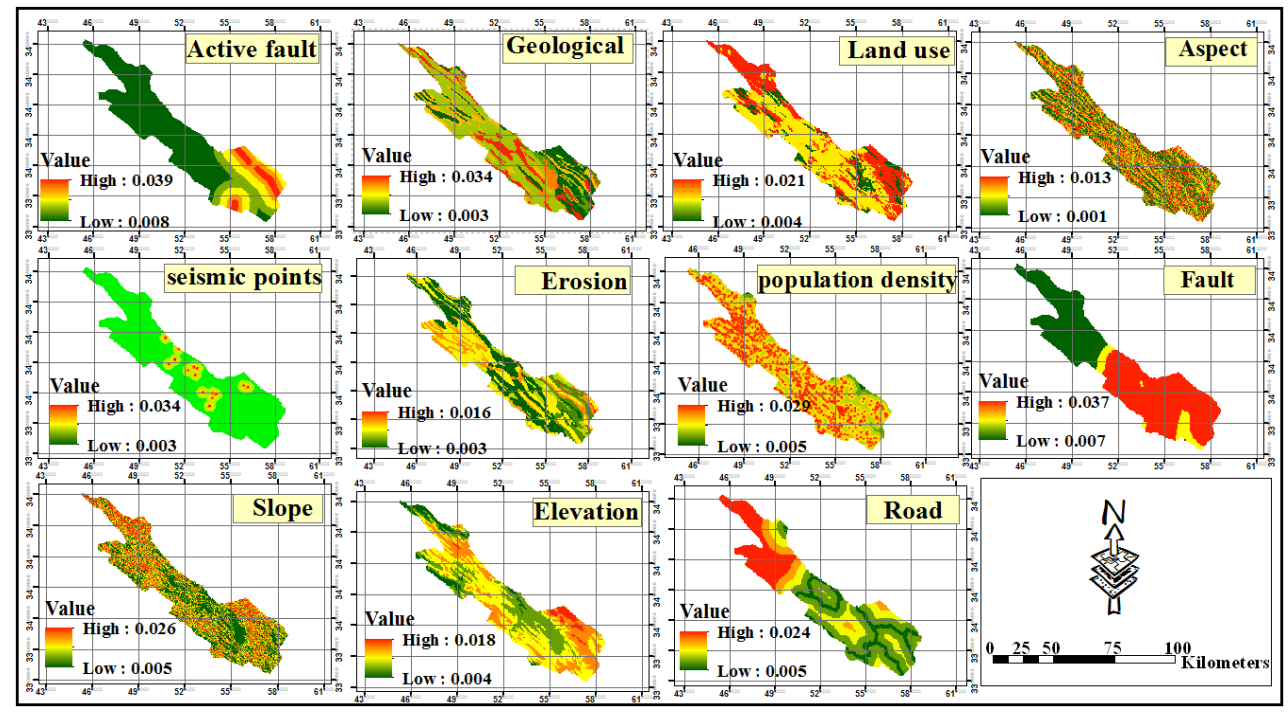

Fig. 5 - Standardized layers

According to the earthquake hotspots extracted map, most of the earthquakes occurred in the vicinity of the main fault lines of the County. According to the land use maps, parts of the County are located on the rugged (resistant) rocks that are more resistant to earthquakes and parts of the County are on the watercourse that has less resistance to the earthquake risk. Based on the geological maps extracted, part of the County's geological structure is of the formation type of Piedmont and of valley terraces deposit which has a very low resistance to earthquakes, and it is located in the central part of the County. And part of the County has the geological structure of the Asmari and Jahrum formation type that is more resistant to earthquakes and this formation is mostly located in the southern part of the County. According to the erosion map, the northern and western parts of the County are more eroded and therefore less resistant to earthquakes. 
The evaluation of earthquake hazard severity in Boyer Ahmad zone based on the seismic survey shows that $8.83 \%\left(353.65 \mathrm{~km}^{2}\right)$ of the county has a very high seismic hazard, and $705 \mathrm{~km}^{2}(17 \%$ of the total area) is without earthquake risk (Table 4).

\section{Evaluation of earthquake hazard severity in Boyer Ahmad}

\begin{tabular}{|c|c|c|c|c|c|c|}
\hline $\begin{array}{c}\text { Earthquake } \\
\text { hazard } \\
\text { severity }\end{array}$ & $\begin{array}{c}\text { Very high } \\
\text { seismicity }\end{array}$ & $\begin{array}{c}\text { High } \\
\text { seismicity }\end{array}$ & $\begin{array}{c}\text { Medium } \\
\text { seismicity }\end{array}$ & $\begin{array}{c}\text { Low } \\
\text { seismicity }\end{array}$ & $\begin{array}{c}\text { Very low } \\
\text { seismicity }\end{array}$ & Total \\
\hline Area $\left(\mathrm{km}^{2}\right)$ & 353.65 & 725.41 & 993.93 & 1225.89 & 705.5 & 4004.38 \\
\hline Percent & 8.83 & 18.12 & 24.82 & 30.62 & 17.61 & 100 \\
\hline
\end{tabular}

Also, among the five cities of Boyer Ahmad, Garab-e Sofla is at very low seismic risk; Chitab and Yasuj are at low seismic risk; Margoon is at medium seismic risk; and Madawan is at high seismic risk (Fig. 6, Table 5). Its long distance from the fault lines of Boyer Ahmad County is the main reason that Garab Sofla is located in the low seismic hazard category. Also, the soil erosive structure in Garab Sofla is of VI type (medium vulnerability), the geological formation is of ASMARI type (medium vulnerability) and its land use is more of the pasturelands type (medium vulnerability). These factors have made the city of Garab Sofla lowly vulnerable and highly resistant to the seismic hazard.

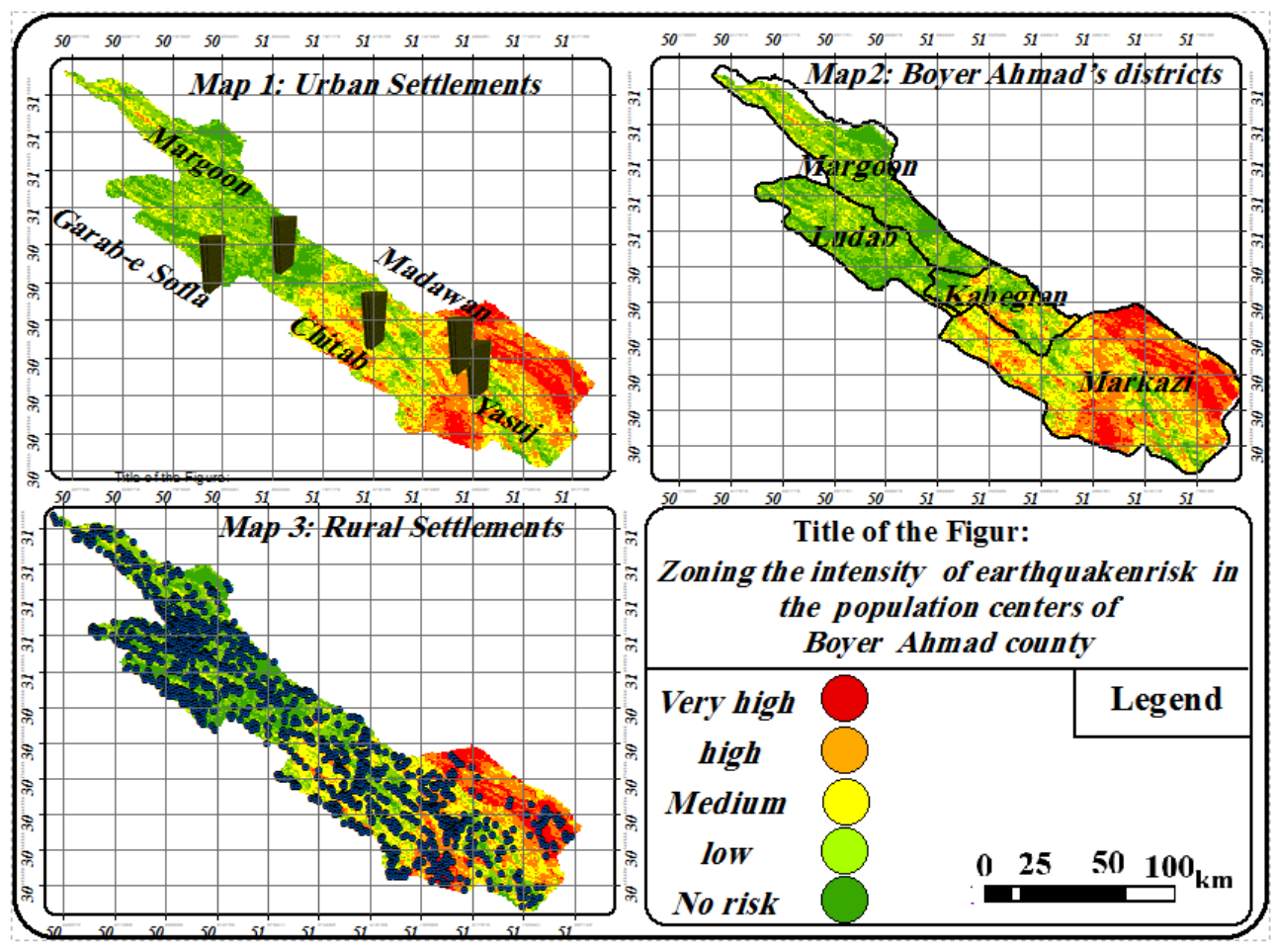

Fig. 6 - Final zoning of the earthquake hazard severity in the populated settlements of Boyer Ahmad

Seismic studies show that the physical development of the city of Yasuj lies on the geological formation of the Fluvial Conglomerate, making it more resistant to earthquakes. The studies of land use and erosional structure also show that the physical development of 
Yasuj is located on erosion class $\mathrm{VI}$ and the land use of rocks and pasturelands partly reduces the risk of earthquake crisis from the city.

Seismic studies also show that the physical development of the city of Chitab lies on the geological formation of ASMARI, making the city of Chitab less vulnerable to the seismic hazard. The studies of land use and erosional structure also show that the physical development of the city of Chitab lies on the erosion III and the land use of rocks and pasturelands reduces the risk of earthquake crisis from the city.

Table 5

Earthquake risk assessment in the urban areas of Boyer Ahmad

\begin{tabular}{|c|c|c|c|}
\hline City & $\begin{array}{c}\text { Severity of } \\
\text { vulnerability }\end{array}$ & Population & $\begin{array}{c}\text { Percentage of vulnerable } \\
\text { population } \\
\text { to total population (\%) }\end{array}$ \\
\hline Garab-e Sofla & Very low & 1164 & 0.38 \\
\hline Yasuj & \multirow{2}{*}{ Low } & 18078 & 6.02 \\
\cline { 3 - 4 } Chitab & 545 & 0.18 \\
\hline Margoon & Medium & 3135 & 1.04 \\
\hline Madawan & High & 18078 & 6.02 \\
\hline
\end{tabular}

The soil erosion structure in Margoon city is of VII type (highly vulnerable), the geological formation is of GURPI type (highly vulnerable), and the land use is of poor pasturelands (medium vulnerable); these factors have made the city of Margoon vulnerable to seismic hazards.

Madavan city also has a high vulnerability to the seismic hazard due to its proximity to the fault lines, locating on the geological formation of MISHAN, the erosion class VII and a poor land layer.

Referring to the location of rural settlements in Boyer Ahmad County, they are mostly in low seismic hazard zones; except for a few of these villages, the rest of the villages are not located on fault lines. However, the concentration of the rural centers of Boyer Ahmad County around the fault lines and the high-risk zones is clearly visible. Therefore, in the event of a high-intensity earthquake, the villages located along the fault lines will be particularly vulnerable, in addition to the villages located directly on the fault lines and in the high-risk areas. Also, the spatial analysis of the vulnerability of rural and oasis areas shows that out of 977 rural and oasis settlements located in Boyer Ahmad, 72 human settlements, i.e. $7.36 \%$, are at very high risk of earthquake risk. 189 villages are also located in the high seismic risk, and 135 villages are located in zones without earthquake risk (Table 6).

Earthquake risk analysis in the rural settlements of Boyer Ahmad

Table 6

\begin{tabular}{|c|c|c|c|}
\hline Type & $\begin{array}{c}\text { Earthquake } \\
\text { hazard severity }\end{array}$ & $\begin{array}{c}\text { Number of rural } \\
\text { settlements }\end{array}$ & $\begin{array}{c}\text { Ratio of the number of villages } \\
\text { and oases to total villages (\%) }\end{array}$ \\
\hline \multirow{3}{*}{$\begin{array}{c}\text { Villages } \\
\text { and } \\
\text { oases }\end{array}$} & No risk & 135 & 13.81 \\
\cline { 2 - 4 } & Low & 338 & 35.59 \\
\cline { 2 - 4 } & Medium & 243 & 24.87 \\
\cline { 2 - 4 } & High & 189 & 19.34 \\
\cline { 2 - 4 } & Very high & 72 & 7.36 \\
\hline
\end{tabular}


Application of Future Studies and Scenario Planning Models in Earthquake Crisis Response Planning

Planning the response to the earthquake crisis in Boyer Ahmad using the scenario planning approach

The results of the cross-impact analysis model in the MICMAC software showed that out of 2980 relationships among the research variables, 863 of the relationships were without effect; 1296 had an effect of one; 907 had the effect of two, and 702 had the effect of four. Overall, $77 \%$ of the research factors were either influenced by each other or they have influenced each other (Table 7).

Table 7

MDI Matrix

\begin{tabular}{|c|c|c|c|c|c|c|c|c|c|}
\hline Indicator & $\begin{array}{c}\text { Matrix } \\
\text { size }\end{array}$ & Iterations & Zeros & Ones & Twos & Threes & $\mathbf{P}$ & $\begin{array}{c}\text { Fill rate } \\
\%\end{array}$ & Total \\
\hline Value & 62 & 2 & 863 & 1296 & 907 & 702 & 4 & 77.52 & 2980 \\
\hline
\end{tabular}

After analyzing the effective factors in reducing the causality and financial vulnerability of earthquake crisis in the population centers of Boyer Ahmad, the research indices were distributed in five main areas of the open cross-impact analysis model to include: key factors, effective factors, negligible variables, outcome variables, and uncertain variables.

Zone one (key factors): indicates the most key strategic priorities in reducing the vulnerability and financial loss of the earthquake crisis in Boyer Ahmad. These factors consist of specialized training of people and staff, intra- and inter-organizational coordination and overlap, budgeting and facilities, research and studies, proper planning, comprehensive earthquake crisis management document, earthquake alerting devices, buildings' retrofitting, construction status on faults, telecommunications, vital infrastructures, main and proper communication lines, and new and durable materials (Fig. 7).

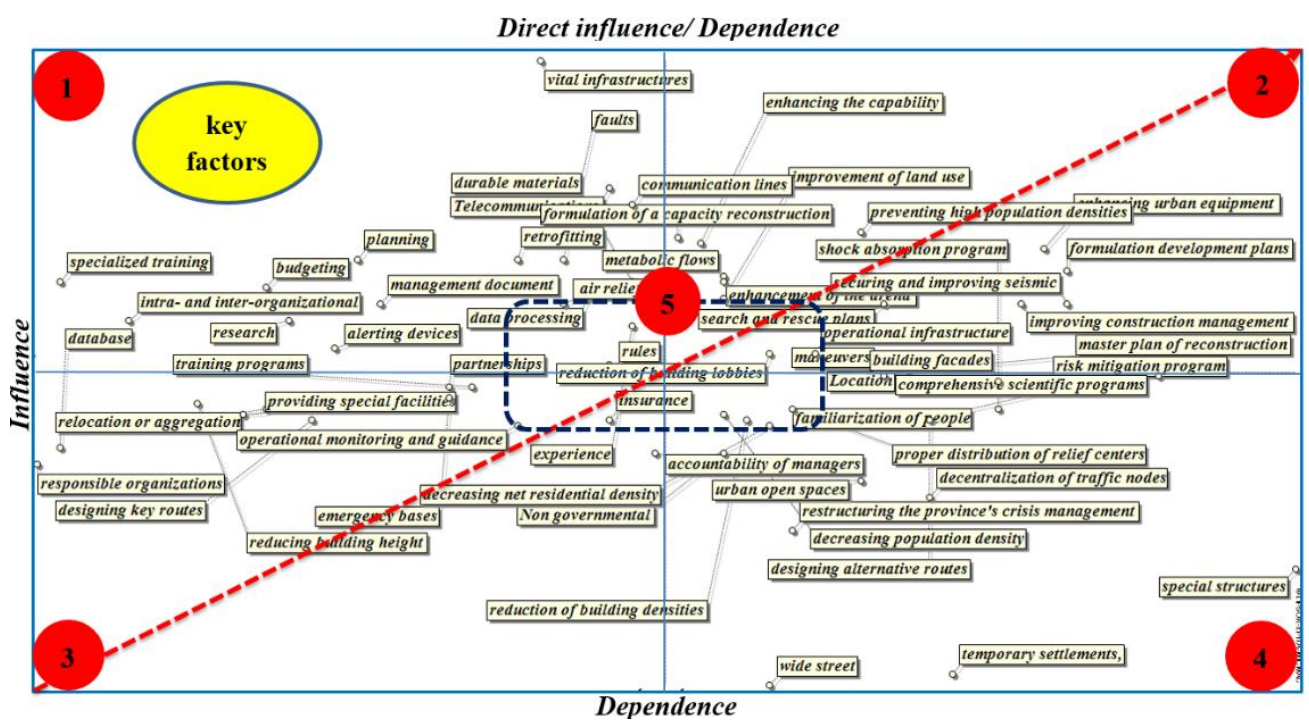

Fig. 7- Distribution diagram of earthquake response propulsion planning in Boyer Ahmad

Source: graphical processes derived from Cross-Impact Analysis model (2019)

Zone two (effective factors): indicates the variables that have both effectiveness and an affectedness role in reducing the causality and financial vulnerability of the earthquake crisis in Boyer Ahmad. These include: enhancing the capability of people and staff, preventing 
high population densities in worn-out textures, formulating search and rescue plans, enhancing urban equipment and infrastructure, securing and improving seismic devices of uses and facilities, improving the construction management and supervision by employing skilled workforce, master plan of reconstruction, development of metabolic flows, enhancement of the arena, formulation and modification of urban and rural development plans appropriate to relative earthquake hazard zoning, sensitive and relevant to the zoning of the relative earthquake risk in the country and the formulation of a capacity reconstruction, remediation and refurbishment plan for worn-out textures.

Zone three (negligible variables): represents the variables that have little effectiveness and affectedness. These factors include: detailed statistics and information about the different features of the city (database), designing key routes in crisis, providing special facilities and incentives, developing partnerships, identifying responsible organizations, reducing the buildings' height (number of floors), developing emergency bases, and the relocation or aggregation of population centres in seismic areas.

Table 8

Direct impact intensity of key and effective factors of cross-impact analysis for disaster response planning

\begin{tabular}{|c|c|c|c|}
\hline Key factors & Effectiveness & Affectedness & $\begin{array}{c}\text { Net } \\
\text { effectiveness }\end{array}$ \\
\hline Specialized training of people and staff & 103 & 104 & -1 \\
\hline $\begin{array}{l}\text { Intra- and inter-organizational coordination and } \\
\text { overlap }\end{array}$ & 86 & 100 & -14 \\
\hline Budgeting and facilities & 110 & 95 & 15 \\
\hline Research and studies & 97 & 96 & 1 \\
\hline Proper planning & 107 & 103 & -4 \\
\hline $\begin{array}{c}\text { Comprehensive earthquake crisis management } \\
\text { document }\end{array}$ & 108 & 88 & 20 \\
\hline Earthquake alerting devices & 97 & 104 & -6 \\
\hline Buildings' retrofitting & 97 & 102 & -5 \\
\hline Construction status on faults & 85 & 97 & -12 \\
\hline Vital infrastructures & 109 & 87 & 22 \\
\hline Main and proper communication lines & 84 & 96 & -12 \\
\hline New and durable materials & 97 & 96 & 1 \\
\hline Telecommunications & 84 & 108 & -24 \\
\hline Effective factors & Effectiveness & Affectedness & $\begin{array}{c}\text { Net } \\
\text { effectiveness }\end{array}$ \\
\hline Enhancing the capability of people and staff & 101 & 60 & 39 \\
\hline $\begin{array}{l}\text { Preventing high population densities in worn-out } \\
\text { textures }\end{array}$ & 100 & 69 & 31 \\
\hline Formulating search and rescue plans & 94 & 70 & 26 \\
\hline Enhancing urban equipment and infrastructure & 109 & 87 & 23 \\
\hline $\begin{array}{c}\text { Securing and improving seismic devices of uses } \\
\text { and facilities }\end{array}$ & 89 & 72 & 17 \\
\hline $\begin{array}{c}\text { Improving construction management and } \\
\text { supervision }\end{array}$ & 105 & 80 & 25 \\
\hline Development of metabolic flows & 100 & 99 & 1 \\
\hline $\begin{array}{c}\text { Formulation and modification of urban and rural } \\
\text { development plans }\end{array}$ & 97 & 74 & 23 \\
\hline Allocation site & 105 & 92 & 13 \\
\hline $\begin{array}{l}\text { Remediation and refurbishment plan for worn-out } \\
\text { textures }\end{array}$ & 115 & 85 & 30 \\
\hline Master plan of reconstruction & 94 & 63 & 31 \\
\hline Enhancement of the arena & 102 & 1001 & 1 \\
\hline
\end{tabular}

Source: statistical processes derived from the Cross-Impact Analysis model (2019)

Zone four (outcome variables): represents the variables that have little effectiveness but high affectedness. These factors include: identifying special structures, identifying and designing emergency and temporary settlements, developing comprehensive scientific 
programs for the psychological and social rehabilitation of the affected people, restructuring the province's crisis management, the proper distribution of urban open spaces, designing alternative routes if major roads are demolished, decentralization of traffic nodes in one area, familiarization of people to understand danger, risk mitigation program, shock absorption program, wide street design, building facades and maintenance, and holding earthquake maneuvers.

Zone five (uncertain variables): these variables are systematically uncertain in the future. They include: data processing and continuous monitoring of critical events and indicators, insurance industry coverage, proper distribution of relief centres, preparation of training programs, improvement of land use compatibility, reduction of building lobbies, popular associations, reduction of building densities, decreasing population density, decreasing net residential density, planning for the accountability of managers, investing in operational infrastructure, appropriate accident prevention rules, development of air relief, utilization of international experience, and operational monitoring and guidance.

The results showed that the most effective factor among the key and effective factors to reduce the causality and financial vulnerability against earthquake crisis in the population centres of Boyer Ahmad are, respectively, the comprehensive earthquake crisis management document, as well as capacity reconstruction, refurbishment, and the reconstruction of worn-out textures (Table 8).

The specialized training of people and staff, and the proper earthquake crisis planning had the highest correlation in the case of indirect factors (Fig. 8). Regarding indirect effects, the organization coordination and overlap (Fig. 9) had the highest correlations in the relationships.

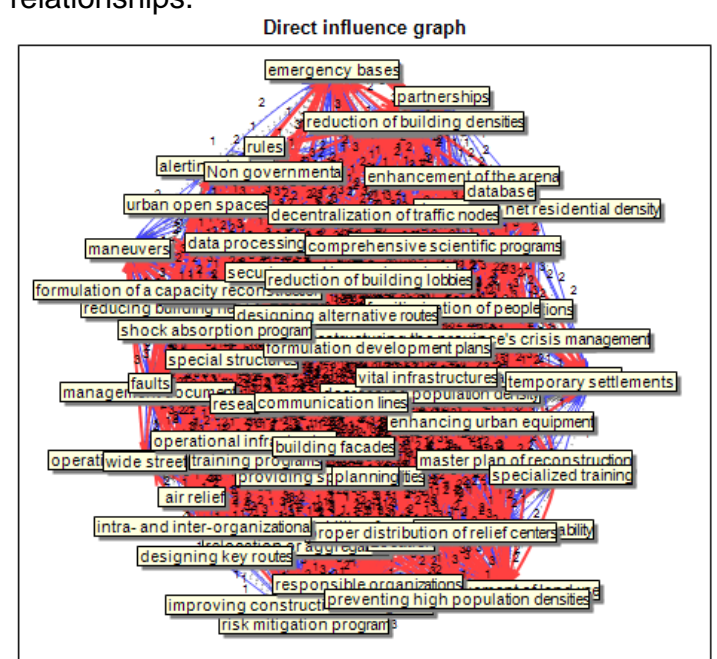

Weakestinfluences

Weak influences

- Relatively strong influencos

- Stronqestinfluences

Fig. 8- Indirect impact of the factors with $100 \%$ coverage and the relationships between them

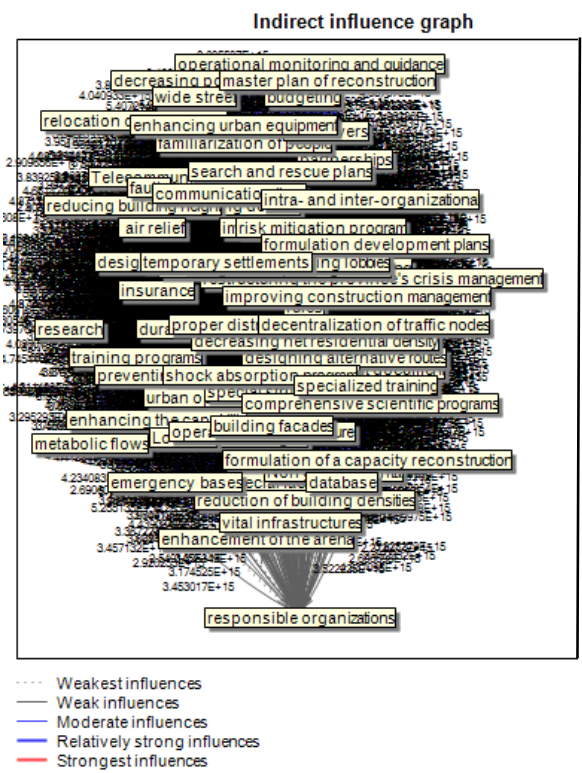

Fig. 9-Direct impact of the factors with $100 \%$ coverage and the relationships between them

Source: graphical processes derived from Cross-Impact Analysis model (2019) 


\section{Formulation of the long-term vision scenario based on the morphological analysis}

After identifying the most important key factors to reduce the causality and financial vulnerability against earthquake crisis, we formulated the hypothesis for each key factor using the experts and elites' views. Then, using the participation of elites and experts, the weights for each of the hypotheses were presented based on two parameters: quantitative $(0<X>100)$ and qualitative (ideal, optimistic, intermediate, and pessimistic) (Table 9).

Table 9

Designed hypotheses and their percentage of validity for each key factor

\begin{tabular}{|c|c|c|c|c|}
\hline \multirow{2}{*}{ Factors } & \multicolumn{4}{|c|}{ Hypothesis } \\
\hline & H1 & $\mathrm{H} 2$ & H3 & $\mathrm{H} 4$ \\
\hline $\begin{array}{l}\text { Comprehensive } \\
\text { document of } \\
\text { earthquake crisis }\end{array}$ & $\begin{array}{l}\text { Compilation of } \\
\text { comprehensive document } \\
\text { for earthquake crisis } \\
(76 \%)\end{array}$ & $\begin{array}{c}\text { Injection of } \\
\text { earthquake crisis } \\
\text { management } \\
\text { principles in all } \\
\text { projects }(15 \%)\end{array}$ & $\begin{array}{l}\text { Failure to formulate a } \\
\text { comprehensive } \\
\text { earthquake crisis } \\
\text { document }(5 \%)\end{array}$ & $\begin{array}{l}\text { Keeping up with } \\
\text { the current trend } \\
(4 \%)\end{array}$ \\
\hline $\begin{array}{l}\text { Earthquake alert } \\
\text { systems }\end{array}$ & $\begin{array}{c}\text { Design and construction } \\
\text { of earthquake alert } \\
\text { systems } \\
(40 \%) \\
\end{array}$ & $\begin{array}{c}\text { Purchase of } \\
\text { earthquake warning } \\
\text { systems }(50 \%)\end{array}$ & $\begin{array}{c}\text { Lack of attention to } \\
\text { purchasing and } \\
\text { designing earthquake } \\
\text { warning systems (5\%) } \\
\end{array}$ & $\begin{array}{c}\text { Keeping the } \\
\text { earthquake alert } \\
\text { strategy current } \\
(5 \%) \\
\end{array}$ \\
\hline $\begin{array}{l}\text { Strengthening the } \\
\text { buildings }\end{array}$ & $\begin{array}{c}\text { Increasing the retrofitting } \\
\text { of buildings } \\
(63 \%)\end{array}$ & $\begin{array}{c}\text { Demolition of } \\
\text { unstable buildings } \\
(17 \%) \\
\end{array}$ & $\begin{array}{l}\text { Lack of attention to } \\
\text { retrofitting buildings } \\
(10 \%) \\
\end{array}$ & $\begin{array}{l}\text { Persistence of the } \\
\text { status quo (10\%) }\end{array}$ \\
\hline $\begin{array}{l}\text { Construction in the } \\
\text { vicinity of faults }\end{array}$ & $\begin{array}{l}\text { Preventing construction at } \\
\text { fault }(80 \%)\end{array}$ & $\begin{array}{c}\text { Prevention of the } \\
\text { construction at } \\
\text { seismic zones (14\%) }\end{array}$ & $\begin{array}{c}\text { Relocation and } \\
\text { integration of } \\
\text { earthquake-prone } \\
\text { population centres }(6 \%)\end{array}$ & $\begin{array}{l}\text { Continuation of the } \\
\text { existing status of } \\
\text { building } \\
\text { construction }(0 \%)\end{array}$ \\
\hline Telecommunications & $\begin{array}{c}\text { Development of modern } \\
\text { telecommunications } \\
\text { infrastructure between } \\
\text { people and government } \\
(60 \%) \\
\end{array}$ & $\begin{array}{c}\text { Development of } \\
\text { telecommunication } \\
\text { infrastructure among } \\
\text { the people } \\
(16 \%) \\
\end{array}$ & $\begin{array}{c}\text { Development of } \\
\text { telecommunications } \\
\text { infrastructure among } \\
\text { government agencies } \\
(20 \%) \\
\end{array}$ & $\begin{array}{l}\text { Persistence of the } \\
\text { status quo (4\%) }\end{array}$ \\
\hline Vital infrastructures & $\begin{array}{l}\text { Increasing investment in } \\
\text { critical infrastructure } \\
(48 \%)\end{array}$ & $\begin{array}{l}\text { Lack of investment in } \\
\text { critical infrastructure } \\
(30 \%)\end{array}$ & $\begin{array}{l}\text { Persistence of the } \\
\text { status quo }(22 \%)\end{array}$ & - \\
\hline $\begin{array}{c}\text { Main and appropriate } \\
\text { routes }\end{array}$ & $\begin{array}{c}\text { Development of road } \\
\text { communication routes } \\
(20 \%)\end{array}$ & $\begin{array}{c}\text { Development of } \\
\text { emergency } \\
\text { helicopters (58\%) }\end{array}$ & $\begin{array}{l}\text { Lack of investment in } \\
\text { communication } \\
\text { infrastructure }(11 \%) \\
\end{array}$ & $\begin{array}{l}\text { Persistence of the } \\
\text { status quo (11\%) }\end{array}$ \\
\hline $\begin{array}{l}\text { Durable and new } \\
\text { materials }\end{array}$ & $\begin{array}{l}\text { Use of new and durable } \\
\text { materials in construction } \\
(51 \%)\end{array}$ & $\begin{array}{c}\text { Use of durable } \\
\text { materials in } \\
\text { construction }(37 \%) \\
\end{array}$ & $\begin{array}{l}\text { No use of new } \\
\text { materials in } \\
\text { construction }(0 \%)\end{array}$ & $\begin{array}{c}\text { Maintaining trends } \\
\text { in building } \\
\text { materials }(12 \%) \\
\end{array}$ \\
\hline Training the citizens & $\begin{array}{c}\text { Development of } \\
\text { earthquake crisis training } \\
\text { facilities }(40 \%)\end{array}$ & $\begin{array}{c}\text { Development of } \\
\text { earthquake learning } \\
\text { culture }(30 \%) \\
\end{array}$ & $\begin{array}{l}\text { Lack of attention to } \\
\text { learning culture }(15 \%)\end{array}$ & $\begin{array}{l}\text { Persistence of the } \\
\text { status quo (15\%) }\end{array}$ \\
\hline $\begin{array}{l}\text { Coordination and } \\
\text { overlap within and } \\
\text { outside the } \\
\text { organization }\end{array}$ & $\begin{array}{l}\text { Relative increase in } \\
\text { coordination between } \\
\text { organizations }(30 \%)\end{array}$ & $\begin{array}{l}\text { Elimination of crisis } \\
\text { management } \\
\text { responsibilities of all } \\
\text { organizations and } \\
\text { creation of a crisis } \\
\text { management } \\
\text { organization }(48 \%)\end{array}$ & $\begin{array}{c}\text { Increased conflict } \\
\text { between organizations } \\
(10 \%)\end{array}$ & $\begin{array}{l}\text { Continuation of } \\
\text { existing status of } \\
\text { communication } \\
\text { between } \\
\text { organizations } \\
(12 \%)\end{array}$ \\
\hline $\begin{array}{l}\text { Budgeting and } \\
\text { facilities }\end{array}$ & $\begin{array}{l}\text { Increasing earthquake } \\
\text { disaster management } \\
\text { credits }(30 \%)\end{array}$ & $\begin{array}{l}\text { Provincial budget } \\
\text { increase in some } \\
\text { dimensions of city } \\
\text { earthquake } \\
\text { management }(53 \%)\end{array}$ & $\begin{array}{l}\text { Earthquake disaster } \\
\text { management credits' } \\
\text { decrease }(8 \%)\end{array}$ & $\begin{array}{l}\text { Persistence of the } \\
\text { status quo }(10 \%)\end{array}$ \\
\hline Research study & $\begin{array}{c}\text { Development of } \\
\text { earthquake related } \\
\text { research in the city }(20 \%)\end{array}$ & $\begin{array}{l}\text { Development of } \\
\text { priority earthquake } \\
\text { related research in } \\
\text { the city }(64 \%) \\
\end{array}$ & $\begin{array}{c}\text { Decrease of } \\
\text { earthquake related } \\
\text { research in the city } \\
(16 \%)\end{array}$ & $\begin{array}{l}\text { Persistence of the } \\
\text { status quo }(0 \%)\end{array}$ \\
\hline Planning & $\begin{array}{l}\text { Macro-planning based on } \\
\text { earthquake crisis (27\%) }\end{array}$ & $\begin{array}{l}\text { Provincial-based } \\
\text { planning based on } \\
\text { organizational } \\
\text { integrity }(66 \%) \\
\end{array}$ & $\begin{array}{c}\text { Provincial-based } \\
\text { planning based on the } \\
\text { lack of organizational } \\
\text { integrity }(7 \%)\end{array}$ & $\begin{array}{l}\text { Persistence of } \\
\text { existing planning } \\
\text { process }(0 \%)\end{array}$ \\
\hline
\end{tabular}


The findings showed that 5000 valid scenarios were identified out of 10,000 scenarios (Table 10). Finally, ten scenarios were selected and analyzed as significant scenarios with $90 \%$ replicability in subsequent scenarios.

\section{Description of extracted scenarios}

Table 10

\begin{tabular}{|c|c|c|}
\hline Row & Explanation & Number of scenarios \\
\hline 1 & Number of scenarios & 10000 \\
\hline 2 & Number of valid scenarios & 5000 \\
\hline 3 & $\begin{array}{c}\text { Number of selected } \\
\text { scenarios }\end{array}$ & 10 \\
\hline
\end{tabular}

Source: statistical analysis of Morphol software (2019)

In the cross-impact analysis of the scenarios, the seventh scenario with eleven ideal hypotheses and two optimistic ones was selected with the highest stability, and then scenario six was selected by changing the two hypotheses with the highest stability and resistance (Table 11).

\section{Quantitative characteristics of extracted scenarios (value=3)}

\begin{tabular}{|c|c|c|c|c|c|}
\hline Row & Scenario & Sustainability & Row & Scenario & Sustainability \\
\hline 1 & S - No. 1 & 2.153 & 6 & No. 6 -S & 2.692 \\
\hline 2 & S -No. 2 & 2.076 & 7 & No. 7 -S & 2.769 \\
\hline 3 & S - No. 3 & 2.230 & 8 & No. 8 -S & 1.461 \\
\hline 4 & S -No. 4 & 2 & 9 & No. 9 -S & 1.384 \\
\hline 5 & S -No. 5 & 1.923 & 10 & No. 10 -S & 1.307 \\
\hline
\end{tabular}

Source: statistical analysis of Morphol software (2019)

Nowadays, one of the strategies for scenario planning is to reduce the probable dimensions of scenarios from millions of scenarios to a few scenarios with high adaptability and ultimately to prepare a scenario to guide the development of a sector or region or country in the future. In this regard, the most desirable scenario to reduce the casualty and financial vulnerability caused by the earthquake crisis in Boyer Ahmad was scenario 7 which had 13 ideal situations to meet the earthquake crisis management goals with proper decision making and accurate implementation of earthquake management strategies (Table 12).

The research findings indicated that one of the key strategies for the reduction of financial damage and human life loss resulting from the earthquake crisis in Boyer-Ahmad County is the formulation of a comprehensive earthquake crisis document. However, not only there is no such a comprehensive earthquake crisis document formulated for urban and rural residences of Boyer-Ahmad County, but also still no comprehensive earthquake crisis document has been formulated at the more general scale (for the whole country) for proper coping with the earthquake crisis.

According to the research geographical analysis, Boyer-Ahmad County is one of the most prone areas of earthquake, while no earthquake warning system has been installed in the population centres of Boyer-Ahmad County and even in the other provinces of Iran. Although the time between the warning and the actual earthquake is only a few seconds or a minute, this time period is important in rescuing people and the negligence to install the warning systems in Boyer-Ahmad County and other population centres in Iran can cause catastrophic damage during the earthquake crisis. 
In recent years, attention has been paid to retrofitting buildings against natural disasters, especially earthquakes, in the urban and rural settlements of Boyer-Ahmad by the Housing Foundation (providing low-interest loans to the applicants for retrofitting, refurbishing, and renovating the buildings). However, the pace of building retrofitting is slow and not fast, so since the safety of the residents is the most important purpose of reinforcing and retrofitting structures against earthquake hazards, it is necessary to retrofit the buildings faster.

Table 12

The most desirable scenario extracted for formulating a road map for Boyer Ahmad to reduce vulnerability to earthquake crisis

\begin{tabular}{|c|c|c|c|}
\hline Row & Scenario & $\begin{array}{l}\text { Scenario } \\
\text { status }\end{array}$ & Key factor \\
\hline 1 & $\begin{array}{l}\text { Formulation of comprehensive document of } \\
\text { earthquake crisis }\end{array}$ & Ideal & $\begin{array}{c}\text { Comprehensive } \\
\text { earthquake } \\
\text { document }\end{array}$ \\
\hline 2 & $\begin{array}{c}\text { Design and construction of earthquake alarm } \\
\text { systems }\end{array}$ & Ideal & Alarm system \\
\hline 3 & Increasing the strength of buildings & Ideal & Strengthening \\
\hline 4 & Prevention of constructions on faults & Ideal & Fault \\
\hline 5 & $\begin{array}{c}\text { Development of telecommunications } \\
\text { infrastructure among government agencies }\end{array}$ & Optimistic & Telecommunications \\
\hline 6 & Increasing investment in critical infrastructure & Ideal & Vital infrastructures \\
\hline 7 & Development of road communication routes & Optimistic & Access \\
\hline 8 & $\begin{array}{l}\text { Use of new and durable materials in } \\
\text { construction }\end{array}$ & Ideal & Building materials \\
\hline 9 & $\begin{array}{c}\text { Development of educational facilities for } \\
\text { citizens and organizations in connection with } \\
\text { the earthquake crisis }\end{array}$ & Ideal & Education \\
\hline 10 & $\begin{array}{c}\text { Elimination of the crisis management } \\
\text { responsibilities of all organizations and creation } \\
\text { of an integrated crisis management } \\
\text { organization }\end{array}$ & Ideal & $\begin{array}{l}\text { Coordination and } \\
\text { overlap within and } \\
\text { outside the } \\
\text { organization } \\
\end{array}$ \\
\hline 11 & $\begin{array}{c}\text { Increasing funding for some important } \\
\text { components of earthquake crisis management } \\
\text { in the city (components of earthquake warning } \\
\text { systems design and building retrofit) } \\
\end{array}$ & Optimistic & $\begin{array}{l}\text { Budgeting and } \\
\text { facilities }\end{array}$ \\
\hline 12 & $\begin{array}{l}\text { Development of priority earthquake related } \\
\text { research at city level (research based on } \\
\text { earthquake damage reduction strategies) }\end{array}$ & Optimistic & Research and study \\
\hline 13 & $\begin{array}{l}\text { Changing the crisis management planning } \\
\text { approach from macro to city level (designing } \\
\text { and planning based on geographical } \\
\text { conditions, fault status, etc. at county level) }\end{array}$ & Ideal & Planning \\
\hline
\end{tabular}

Source: statistical analysis of Morphol software (2019)

In the urban settlements of Iran and Boyer-Ahmad County, not only the fault setbacks and the rural areas have not been specified, but also no attention has been paid to the fault setbacks to prevent the construction on them. In fact, specifying the legal fault setbacks in the urban and rural settlements of Boyer-Ahmad County prevents the irregularities in construction that have led to the construction of important buildings on the fault setback and it identifies safe locations in the cities. Therefore, the plan to determine the legal fault setbacks in the population centers of Iran and Boyer-Ahmad County can at least prevent 
continuing the construction of important centres on faults, compensating the 50-year negligence over time.

The telecommunications infrastructure in the population centres of Boyer-Ahmad is in poor condition, while communication disruption is another crisis after the earthquake, and like the earthquake crisis, it can create another crisis. Hence, the development of the communication infrastructure can be considered as a targeted strategy for coordinating aid provision, as well as taking effective measures during and after the earthquake crisis to reduce vulnerability in the population centres of Boyer-Ahmad County.

Although in recent years attention has been paid to the strengthening and developing of critical infrastructure (health network, emergency, rescue centres, fire stations, etc.), the critical infrastructure in Boyer Ahmad is still poor. In fact, the main arteries of the BoyerAhmad County, which generally include health network, emergency, rescue centres, military centres, transmission lines (water, oil, and gas), as well as telecommunications and media networks, as the main components of the urban and rural settlements of Boyer-Ahmad, should be a top investment priority. In other words, if the critical infrastructure was seriously vulnerable and failed, the urban activities or relief operations would be paralyzed in times of crisis, thus increasing the cost of life and financial losses.

All urban and rural settlements of Boyer-Ahmad have access to transportation lines, including roads, but these roads are highly vulnerable due to their inability to withstand the earthquake crisis and because of the mountainous nature of the County, many roads would be blocked during the earthquake crisis due to the mountain falls and breaking the bridges. Therefore, the development and strengthening of road lines in the population settlements of Boyer-Ahmad County (due to the importance of time for quick access to the injured) can play an important role in providing services to the citizens in an earthquake crisis.

Unfortunately, Iran, as well as Boyer-Ahmad County, has many problems concerning the construction and the supervision of construction. The use of weak and instable materials, the inadequate supervision of buildings, especially in the case of mass housing, and the very simple surveillance have caused extensive building demolition in events like an earthquake. In fact, the buildings in Boyer-Ahmad County look durable with high quality and up-to-date materials, but the materials used in the buildings are of poor quality and old materials, and even their potential against earthquakes has not been calculated. Thus, in order to reduce the severity of buildings demolition in the event of an earthquake crisis, the standardization of building materials should be considered, and the building materials should be modern and of high quality.

Today, there are no programs for informing, for raising awareness, and for educating the citizens in the urban and rural settlements of Boyer-Ahmad County, and even in Iran, to deal with earthquake crisis preparedness. There is very little training given to people in dealing with the earthquake crisis, and it is only given in schools. In fact, education is a very important issue that must be at the level of both the authorities and the public, and the training must be face-to-face, complete and comprehensive, through the national media (television channels), the cyberspace, administrative and private organizations, educational centers (universities and schools), as well as at the scale of urban and rural areas, which significantly reduces the damage caused by earthquakes.

In Iran and Boyer-Ahmad, there is not a single organization that takes all earthquake crisis measures to properly manage the crisis, and all influential organizations in earthquake management are involved in relief operations that cause irregularities and inadequate earthquake management. Therefore, the lack of unified and integrated management during the earthquake crisis is one of the most important problems of the earthquake zones in Iran and Boyer-Ahmad County. Thus, establishing a single crisis management as well as 
identifying the main crisis management centre and assigning the tasks of each organization during the earthquake crisis will lead to a proper crisis management during the earthquake.

Another strategy adopted to deal with the damages caused by the earthquake crisis in Iran and in Boyer-Ahmad County is to pay attention to the practical and priority issues related to the earthquake crisis in Boyer-Ahmad County. In fact, most of the research on the earthquake crisis in Boyer-Ahmad has no practical application and it does not address the priority problems and challenges associated with the earthquake in this County, so the issue of earthquake research should mainly be followed by applied research so that the County problems in the earthquake crisis and the priority issues can be addressed.

There is no planning for the proper management of the funds and resources allocated to managing the potential earthquake disasters, as well as to the development of infrastructure, equipment, and facilities related to the potential earthquake crisis in Iran and Boyer-Ahmad. In fact, for the proper management of the earthquake crisis, the budget for each priority sector needs to be identified first, and then priority actions, facilities, and equipment will be identified in the event of an earthquake crisis.

In addition, most of the planning to deal with the earthquake crisis in Iran is done without any consideration of the geographical, ecological, and demographic situation of the provinces and cities of the country. If a plan is formulated to deal with the earthquake crisis for the County of Boyer-Ahmad, the program will not consider the geographical, ecological, demographic, political, economic, and cultural situation of the County. However, all the cities of Iran are different in geographical, ecological, etc. dimensions. Thus, if planning for the County of Boyer-Ahmad needs to be formulated, it must be tailored to the different situations of Boyer-Ahmad in order to achieve a comprehensive and optimal planning.

\section{Conclusions}

The results revealed that the main cause of seismicity in the urban and rural settlements of Boyer Ahmad is the location of the settlements in the vicinity of Zagros fault with $321 \mathrm{~km}$ length. The results also showed that out of the total area of Boyer Ahmad, $1079.06 \mathrm{~km}^{2}$, i.e., $26.95 \%$, is at risk of earthquake; furthermore, of the cities of Boyer Ahmad, Madwan is at risk of earthquake, and of 997 villages and oases, 261 are at risk of earthquake.

Accordingly, the most important factors extracted to reduce the casualty and financial vulnerability of human settlements in Boyer Ahmad against the earthquake crisis indicate that a comprehensive earthquake crisis management document should be developed at the city level first, followed by earthquake warning systems and earthquake-resistant building design and installation. The constructions on faults should be prevented; telecommunications in urban and rural organizations and settlements have to be developed and strengthened; and the investment in vital urban and rural settlements should be enhanced. All urban and rural settlements should have access to communication routes; the quality of building materials should be improved; durable and classy building materials have to be used. Citizens and professionals should be educated how to deal with the earthquake hazard. To co-ordinate organizations against the earthquake crisis, only one specific organization called the City Crisis Management Agency has to be established; funding an additional budget in some components of earthquake management, including the designing of an earthquake warning systems and building retrofitting should be augmented. Priority research on the earthquake crisis at city level should be based on solutions to the earthquake damage at city level, and planning for the earthquake crisis management should be changed from a macro to a city-based approach while planning only at city level and within a specific organization. 
Application of Future Studies and Scenario Planning Models in Earthquake Crisis Response Planning

\section{References}

BAÑULS V. A., TUROFF M. (2011), Scenario construction via Delphi and crossimpact analysis, Technological Forecasting and Social Change 78 (9), 1579-1602.

BELL W. (2002), A community of futurists and the state of the futures field, Futures 34, 235-247.

BELL W. (2003), Foundations of Futures Studies: History, Purposes, and Knowledge, Routledge, London.

BRADFIELD R., WRIGHT G., BURT G., CAIRNS G., VAN DER HEIJDEN K. (2005), The origins and evolution of scenario techniques in long range business planning, Futures 37 (8), 795-812.

CHERMACK T. J. (2005), Studying scenario planning: Theory, research suggestions, and hypotheses, Technological Forecasting and Social Change 72 (1), 59-73.

DE RISI R., BHATTACHARYA S., GODA K. (2018), Seismic performance assessment of monopile-supported offshore wind turbines using unscaled natural earthquake records, Soil Dynamics and Earthquake Engineering 109, 154-172.

DONG L., SHAN J. (2013), A comprehensive review of earthquake-induced building damage detection with remote sensing techniques, ISPRS Journal of Photogrammetry and Remote Sensing 84, 85-99.

DOOCY S., JACQUET G., CHEREWICK M., KIRSCH T. D. (2013), The injury burden of the 2010 Haiti earthquake: A stratified cluster survey, Injury 44 (6), 842-847.

EINALI J., YEGANEH B. M., CHERAGHI M., FEYZOLAHPOUR M. (2020), Evaluating the effects of reconstruction of the damaged villages in the 2002 earthquake in Avaj, Iran, International Journal of Disaster Risk Reduction 43, 101373.

FOULGER G., WILSON M., GLUYAS J., JULIAN B., DAVIES R. (2017), Global review of human-induced earthquakes, Earth-Science Reviews 178, 438-514.

GAUSEMEIER J., FINK A., SCHLAKE O. (1998), Scenario Management: An Approach to Develop Future Potentials, Technological Forecasting and Social Change 59 (2), 111-130.

GENELETTI D. (2012), Environmental Assessment of Spatial Plan Policies through Land Use Scenarios: A Study in a Fast-Developing Town in Rural Mozambique, Environmental Impact Assessment Review 32 (1), 1-10.

GLENN J. C., GORDON T. J. (eds.) (2009), Futures Research Methodology Version 3.0, The Millennium Project, Retrieved from: www.millennium-project.org.

GODET M., DURANCE P. (2011), Strategic Foresight for Corporate and Regional Development, UNESCO, Retrieved from: www.laprospective.fr.

HAASNOOT M., MIDDELKOOP H. (2012), A history of futures: A review of scenario use in water policy studies in the Netherlands, Environmental Science \& Policy 1920, 108-120.

HADDOW G. D., BULLOCK J. A., COPPOLA D. P. (2017), 2 - Natural and Technological Hazards and Risk Assessment, in: Haddow G. D., Bullock J. A., Coppola D. P., Introduction to Emergency Management, Butterworth-Heinemann, Oxford, pp. 33-77.

HELMER O. (1977), Problems in futures research: Delphi and causal cross-impact analysis, Futures 9 (1), 17-31.

HINES A. (2002), A practitioner's view of the future of futures studies, Futures 34 (3-4), 337-347.

ICRC (2011), ICRC Annual Report 2010, International Committee of the Red Cross, Retrieved from: www.icrc.org.

JOHANSEN I. (2018), Scenario modelling with morphological analysis, Technological Forecasting and Social Change 126, 116-125.

KADAM S., BANDYOPADHYAY P. K. (2020), Modelling passenger interaction process (PIP) framework using ISM and MICMAC approach, Journal of Rail Transport Planning \& Management 14, 100171.

KAHANDAWA K.A.R.V.D., DOMINGO N. D., PARK K. S., UMA S. R. (2018), Earthquake damage estimation systems: Literature review, Procedia Engineering 212, 622 628. 
KASSEM M. M., NAZRI F. M., FARSANGI E. N. (2019), Development of seismic vulnerability index methodology for reinforced concrete buildings based on nonlinear parametric analyses, MethodsX 6, 199-211.

KUMAR H., SINGH M. K., GUPTA M. P. (2019), A policy framework for city eligibility analysis: TISM and fuzzy MICMAC-weighted approach to select a city for smart city transformation in India, Land Use Policy 82, 375-390.

KUOSA T. (2011), Evolution of futures studies, Futures 43 (3), 327-336.

LIU H., ZHANG D., WEI Q., GUO Z. (2017), Comparison study on two postearthquake rehabilitation and reconstruction modes in China, International Journal of Disaster Risk Reduction 23, 109-118.

MCHALE J., CORDELL MCHALE M. (1976), An assessment of futures studies worldwide, Futures 8 (2), 135-145.

MENDONÇA S., PINA E CUNHA M., RUFF F., KAIVO-OJA J. (2009), Venturing into the Wilderness: Preparing for Wild Cards in the Civil Aircraft and Asset-Management Industries, Long Range Planning 42 (1), 23-41.

NIINILUOTO I. (2001), Futures studies: science or art?, Futures 33 (5), 371-377.

ÖNER M. A. (2010), On theory building in Foresight and Futures Studies: A discussion note, Futures 42 (9), 1019-1030.

PANULA-ONTTO J., LUUKKANEN J., KAIVO-OJA J., O'MAHONY T., VEHMAS J., VALKEALAHTI S., BJÖRKQVIST T., KORPELA T., JÄRVENTAUSTA P., MAJANNE Y., KOJO M., AALTO P., HARSIA P., KALLIOHARJU K., HOLTTINEN H., REPO S. (2018), Cross-impact analysis of Finnish electricity system with increased renewables: Long-run energy policy challenges in balancing supply and consumption, Energy Policy 118, 504-513.

PARISI F., AUGENTI N. (2013), Earthquake damages to cultural heritage constructions and simplified assessment of artworks, Engineering Failure Analysis 34, 735760 .

RAMÍREZ R., SELSKY J. W. (2014), Strategic Planning in Turbulent Environments: A Social Ecology Approach to Scenarios, Long Range Planning 49 (1), 90-102.

RODGERS J., SU G., QI W., MILLEDGE D., DENSMORE A., DAVIS C., ENGLAND P., YOUNG J., CAO Y., CHAKOS A., LI X., SIM T., SO E., PARSONS B., SUN L., YU J., GUO C. (2020), Creating an earthquake scenario in China: A case study in Weinan City, Shaanxi province, International Journal of Disaster Risk Reduction 42, 101305.

SARDAR Z. (2010), The Namesake: Futures; futures studies; futurology; futuristic Foresight-What's in a name?, Futures 42 (3), 177-184.

SOŁTYSIK B., FALBORSKI T., JANKOWSKI R. (2017), Preventing of earthquakeinduced pounding between steel structures by using polymer elements - experimental study, Procedia Engineering 199, 278-283.

SON H. (2015), The history of Western futures studies: An exploration of the intellectual traditions and three-phase periodization, Futures 66, 120-137.

TAGHVAEI M., HOSSEINEKHAH H. (2018), Tourism Development Planning Based on Futures Studies and Scenario Case Study: Yasouj, Tourism Planning and Development 6 (23), 8-30.

THORLEUCHTER D., VAN DEN POEL D. (2014), Semantic compared cross impact analysis, Expert Systems with Applications 41 (7), 3477-3483.

TREUER G., BROAD K., MEYER R. (2018), Using simulations to forecast homeowner response to sea level rise in South Florida: Will they stay or will they go?, Global Environmental Change 48, 108-118.

UNDP (2004), A global report: Reducing Disaster Risk, A Challenge for Development, United Nations Development Programme, New York.

VALAGUSSA A., FRATTINI P., CROSTA G. B. (2014), Earthquake-induced rockfall hazard zoning, Engineering Geology 182 (Part B), 213-225.

VECCHIATO R. (2019), Scenario planning, cognition, and strategic investment decisions in a turbulent environment, Long Range Planning 52 (5), 101865.

VERMA M., BANSAL B. K. (2012), Earthquake precursory studies in India: Scenario and future perspectives, Journal of Asian Earth Sciences 54-55, 1-8. 
Application of Future Studies and Scenario Planning Models in Earthquake Crisis Response Planning

VILLACORTA P. J., MASEgOSA A. D., CASTELLANOS D., LAMATA M. T. (2014), A new fuzzy linguistic approach to qualitative Cross Impact Analysis, Applied Soft Computing 24, 19-30.

VITORINO H., RODRIGUES H., COUTO C. (2020), Evaluation of post-earthquake fire capacity of reinforced concrete elements, Soil Dynamics and Earthquake Engineering 128, 105900.

YARI A., ZAREZADEH Y., OSTADTAGHIZADEH A. (2019), Prevalence of Fatalistic Attitudes toward Earthquake Disaster Risk Management in Citizens of Tehran, Iran, International Journal of Disaster Risk Reduction 38, 101181.

ZARRABI A., MOHAMMADI J., HOSSEINI KHAH H. (2015), Crisis management strategy for uses, With an emphasis on urban-sensitive uses (case study: Yasouj), Spatial Planning 6 (3), 37-58.

ZHANG Y., WENG W. G., HUANG Z. L. (2018), A scenario-based model for earthquake emergency management effectiveness evaluation, Technological Forecasting and Social Change 128, 197-207.

ZOLFAGHARI M. R., PEYGHALEH E. (2016), Development of optimization-based probabilistic earthquake scenarios for the city of Tehran, Computers \& Geosciences 86, 129-145.

Initial submission: 20.10 .2019

Revised submission: 03.09.2020

Final acceptance: 22.12 .2020

Correspondence: Department of Geography and Urban Planning, University of Isfahan, Azadi square, 8174673441 Isfahan, Iran.

Email: asgharzarrabi2000@gmail.com 
